\title{
ANALISA PENGARUH LAMA FERMENTASI TERHADAP KADAR BIOETANOL PADA MESIN DESTILATOR MODEL REFLUX
}

\author{
Muchlas Ichsan \\ Fakultas Teknik, Program Studi Teknik Mesin \\ Universitas Muria Kudus. \\ Email: Ichsan.much@gmail.com. \\ Bachtiar Setya Nugraha \\ Fakultas Teknik, Program Studi Teknik Mesin \\ Universitas Muria Kudus \\ Email: setyanugraha_72@yahoo.co.id \\ Rochmad Winarso \\ Fakultas Teknik, Program Studi Teknik Mesin \\ Universitas Muria Kudus \\ Email: boswin@gmail.com.
}

\begin{abstract}
ABSTRAK
Produksi etanol melalui beberapa proses tahapan dari pemarutan bahan baku (ketela pohon) dilanjut dengan komposisi yang sudah ditentukan, kemudian proses fermentasi, dan dilanjutkan tahapan distilasi. Komposisi fermentasi terdiri dari: ketela pohon, enzym alfa amylase, enzym gluco amylase, NPK, urea, dan ragi (yeast). Lama fermentasi berpengaruh terhadap kadar hasil destilasi, produksi etanol dari hasil destilasi dilakukan untuk mendapatkan kadar hasil etanol yang tinggi. Harapannya sumber energi alternatif ini merupakan sumber energi yang terbarukan dan menjadi energi alternatif bagi masyarakat. Penelitian bertujuan untuk mengetahui lama fermentasi ketela pohon yang paling baik untuk menghasilkan kadar etanol yang tinggi dengan mesin destilator model reflux. Metode yang digunakan adalah pengambilan data dengan mengadakan pengujian dan pengamatan terhadap lama fermentasi terhadap kadar etanol. Serta mengunakan metode pengujian secara langsung dan pengumpulan data kadar etanol hasil distilasi cairan fermentasi 3, 5, dan 7 hari. Dari kesimpulan hasil rata-rata data lama fermentasi 3, 5, dan 7 hari yang menghasilkan kadar etanol paling tinggi yaitu dari lama fermentasi 7 hari yang mengasilkan kadar etanol tertinggi yaitu: $92 \%$ etanol. Dengan komposisi fermentasi: ketela pohon = $10 \mathrm{~kg}$, air $=15$ liter, enzym alfa amylase $=10 \mathrm{ml}$, enzym gluco amylase $=10 \mathrm{ml}$, NPK $=5$ gram, Urea $=$ 20 gram, ragi $($ yeast $)=15$ gram
\end{abstract}

Kata kunci: etanol, ketela pohon, lama fermentasi.

\begin{abstract}
Production etanol pass several stages process from basic commodity rasping (tapioca) after that with composition that determined, then fermentation process, and continued distillation stage. fermentation composition consists of: tapioca, enzym alpha amylase, enzym gluco amylase, NPK, urea, and yeast (yeast). long influential fermentation towards result degree destilasi, production etanol from result destilasi done to get result degree etanol tall. this alternative energy source the hope is energy source renewable and be alternative energy for society. watchfulness aims to detect long tapioca fermentation best to produce degree etanol tall mechanically destilator model reflux. Method that used data taking with hold testing and observation towards long fermentation towards degree etanol. with testing method directly and degree data collecting etanol fermentation liquid distillation result 3, 5, and 7 days. From fermentation long data average result conclusion 3, 5, and 7 days that produce degree etanol highest that is from long fermentation 7 days prodact degree etanol highest that is: $92 \%$ etanol. with fermentation composition: tapioca $=10 \mathrm{~kg}$, water $=15$ litres, enzym alpha amylase $=10 \mathrm{ml}$, enzym gluco amylase $=10 \mathrm{ml}, \mathrm{NPK}=5 \mathrm{gram}$, urea $=20$ gram, yeast $($ yeast $)=15$ gram .
\end{abstract}

Keywords: etanol, tapioca, duration of fermentation. 


\section{PENDAHULUAN}

Minyak bumi merupakan salah satu sumber energi yang tidak dapat diperbaharui atau non renewable. Keberadaannya hingga saat ini menempati urutan pertama sebagai sumber energi. Salah satu turunan minyakbumi yang banyak digunakan pada industri kecil dan rumah tangga adalah minyak tanah. Upaya pemerintah untuk mengalihkan penggunaan minyak tanah ke bahan bakar lain perlu didukung. Saat ini pengalihan penggunaan minyak tanah ke bahan bakar gas banyak menemui kendala antara lain banyaknya kasus kebakaran yang disebabkan oleh bahan bakar gas, karena sifat gas yang selalu memenuhi ruangan sehingga apabila terjadi percikan api dalam kompor akan memicu kebakaran di sekitarnya.

Oleh karena itu pengalihan atau konversi minyak tanah tidak harus ke bahan bakar gas tetapi juga dapat etanol yang bersifat lebih ramah lingkungan dan tidak membahayakan lingkungan. Etanol mempunyai kelebihan selain ramah lingkungan, penggunaannya sebagai bahan bakar kompor terbukti lebih hemat dan efisien proses pembakarannya. Selain itu, pembuatannya bisa dilakukan di rumah dengan mudah dan lebih ekonomis dibandingkan menggunakan minyak tanah.

Etanol merupakan cairan hasil proses fermentasi gula dari sumber karbohidrat (pati) menggunakan bantuan mikro organisme. Produksi etanol dari tanaman yang mengandung pati atau karbohidrat, dilakukan melalui proses konversi karbohidrat menjadi gula (glukosa). Pada hidrolisis enzimatis dikenal ada dua metodeyaitu SHF(separate hydrolysis fermentation)dan SSF(Simultaneous Saccarification Fermentation). Metode SSF(Simultaneous Saccarification Fermentation) menjadi sangat penting untuk dikembangkan karena dapat mempersingkat proses pembuatan etanol [4].

Salah satu alternatif yang dapat digunakan adalah memanfaatkan pati yang terkandung dalam singkong karet (Manihot glaziovii). Singkong karet merupakan salah satu jenis singkong pohon yang mengandung senyawa beracun, yaitu asam sianida $(\mathrm{HCN})$, sehingga tidak diperjualbelikan dan kurang dimanfaatkan olehmasyarakat. Tanaman singkong karet ini dapat menghasilkan ubi dengan berat hampir empat kali lipat dibandingkan singkong biasa sehingga apabila dijadikan bahan baku pembuatan etanol sangat layak dari segi ketersediaannya, artinya untuk ketersediaan sebagai bahan baku baku cukup aman [2].

\section{METODOLOGI PENELITIAN}

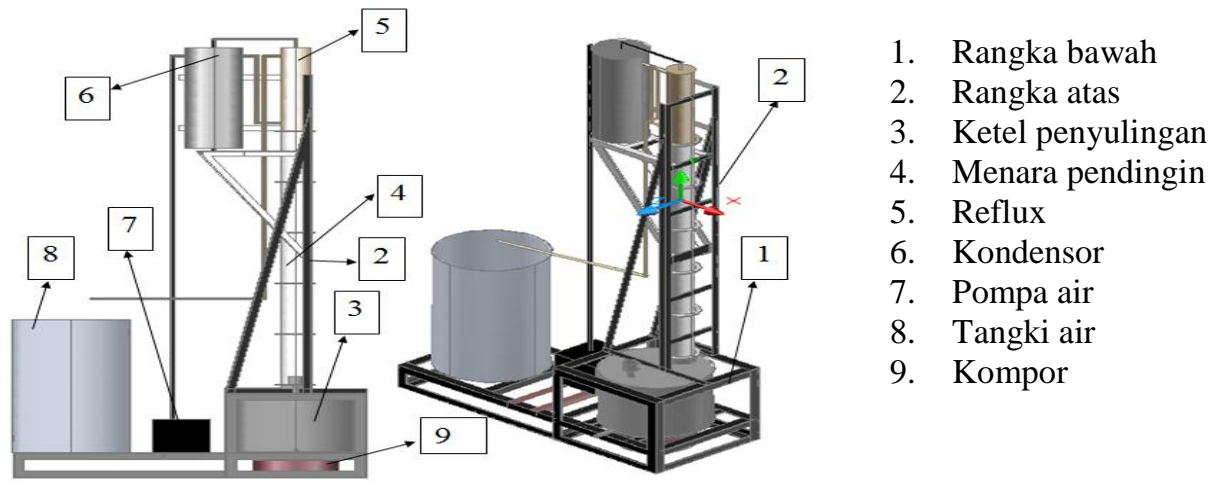

Gambar 1. Mesin Destilator Etanol Model Reflux

1. Rangka bawah Berfungsi untuk penguat rangka atas dan untuk dudukan ketel penyulingan serta tangki air.

2. Rangka atas berfungsi untuk dudukan menara pendingin, kondensor dan reflux.

3. Ketel Penyulingan berfungsi untuk memisahkan kadar air dengan etanol.

4. Menara pendingin berfungsi sebagai penyetabil suhu pada reflux $\left(78^{0} \mathrm{C}\right)$

5. Reflux berfungsi untuk menurunkan suhu.

6. Kondensor berfungsi untuk merubah uap menjadi air.

7. Pompa air berfungsi untuk memindahkan air kedalam tangki

8. Tangki air berfungsi sebagai penampung air.

9. Kompor berfungsi sebagai sumber energi panas.

Alat yang digunakan adalah ember berukuran 15 liter 2 buah,Panci drum ukuran 50 liter 1buah.Kompor gas 1 buah,Saringan 2 buah,Tong plastik ukuran 25 liter : 6 buah,Botol aqua bekas ukuran 1,5 liter 12 buah,Mesin destilator 1 buah,Selang panjang $50 \mathrm{~cm} 6$ buah,Karet ban / tali rafia12 
buah,Plastik12 buah,Mesin pemarut singkong1 buah, Pisau $\quad$ : 2 buah,Timbangan digital 1 buah,Kain 1 buah. Sedangkan bahan yang digunakan adalah Ketela $60 \mathrm{Kg}$, Air $90 \mathrm{Kg}$.Ragi roti 90 gram,Enzym Alfa Amylase 60 gram,Enzym Gluko Amylase 60 gram.Urea 120 gram,NPK 30 gram.

\subsection{Prosedur Penelitian}

\subsubsection{Tempat Dan Waktu Penelitian}

Tempat pengujian dilakukan di workshop (laboratorium UMK), Waktu penelitian dengan bahan baku ketela pada tanggal 29, 31, Agustus, dan 2 September 2014 Berdasarkan penelitian dan teori yang sudah ada dan saya mencoba untuk mempraktekannya, dan melakukan perbandingan dari hasil yang sudah ada pada sebelumnya, sehingga dapat melakukan proses destilasi pada saat melakukan fermentasi pada perbandingan atau pencampuran bahan-bahan yang dicampurkan pada saat ferme ntasi (komposisi), dan dengan suhu yang tepat saat melakukan pemasakan. Sekaligus untuk mencari lama waktu proses fermentasi yang tepat untuk menghasilkan bioetanol dengan kadar yang maksimal

\subsubsection{Langkah Proses Penelitian}

Menyiapkan ubi kayu/singkong yang sudah tua sebanyak $10 \mathrm{~kg}$, usahakan pada saat pemprosesan ubi kayu tidak lebih dari 3 hari sejak di cabut dari kebun,Mengupas singkong dan kemudian cuci dengan air bersih,Pemarutan singkong menggunakan parutan kelapa,Kemudian parutan singkong dicampur dengan air sebanyak 15 liter (1,5Xberat bahan baku) dan diaduk hingga merata. Selanjutnya masukkan kedalam coocker tank untuk segera di masak,Adonan singkong dimasak sambil terus menerus diaduk selama satu jam menggunakan kayu pengaduk.Pengadukan dilakukan hingga adonan mengental seperti jelly dan mulai terasa berat untuk diaduk (proses gelatinasi). Cek suhu adonan menggunakan termometer celup. Apabila suhu telah mencapai $80^{\circ}-85^{\circ} \mathrm{C}$ masukkan $10 \mathrm{ml}$ Enzym Alfa Amylase sambil terus diaduk sampai adonan berubah menjadi lebih cair seperti sup dan terasa ringan ketika diaduk. Pertahankan suhu pada $90^{\circ}-95^{\circ} \mathrm{C}$ selama 1 jam dengan cara mengatur besar kecilnya api. Tahapan ini disebut Proses Likuifikasi,Mematikan kompor, biarkan adonan mendingin hingga mencapai suhu rendah, yaitu $60^{\circ} \mathrm{c}$. Pada suhu itu masukkan $10 \mathrm{ml}$ Enzym Gluco Amylase sambil diaduk hingga merata. Pertahankan adonan pada suhu $60^{\circ} \mathrm{C}$ selama 1 jam, kemudian biarkan adonan mendingin hingga suhu sekitar $27^{\circ}-30^{\circ} \mathrm{C}$. Tahapan ini disebut Proses Sakarifikasi. Pada kondisi ini gula komplex dipecah lagi menjadi cairan gula sederhana dengan proses rendah (12\%-14\%), Setelah cairan gula sederhana mendingin $\left(27^{0}-30^{\circ} \mathrm{C}\right)$, masukkan cairan tersebut kedalam tong fermentor. Selanjutnya masukkan 20 garm pupuk Urea dan 5 gram NPK aduk hingga tercmpur merata pada cairan. Setelah itu masukkan ragi roti sebanyak 15 gram dan aduk hingga merata. Kemudian tutup tabung fermentor dengan rapat/kedap udara dan menyalurkan selang pada wadah yang sudah diisi air (untuk mengetahui reaksi dari fermentasi/keluarnya gelembung udara). Fungsi pupuk urea dan NPK adalah sebagai nutrisi bagi aktivitas ragi. Keseluruhan aktivitas ini memerlukan ketelitian agar bahan baku tidak terkontaminasi oleh mikroba lainnya, komposisi pada saat fermentasidengan bahan baku ubi kayu/singkong :

a. Pengujian 3 hari dengan komposisi (enzym, ragi, NPK, urea)

Air $=15 \mathrm{~kg}$,Singkong $=10 \mathrm{~kg}$,Enzym Alfa Amylase $=10 \mathrm{ml}$.Enzym Gluco Amylase $=10$ $\mathrm{ml}$, Ragi $=15$ gram,NPK $=5$ gram,Urea $=20$ gram.

b. Pengujian 5 hari (Fermentasi dengan waktu 120), dengan komposisi (enzym, ragi, NPK, urea). Air $=15 \mathrm{~kg}$,Singkong $=10 \mathrm{~kg}$,Enzym Alfa Amylase $=10 \mathrm{ml}$,Enzym Gluco Amylase $=10$ $\mathrm{ml}$, Ragi $=15$ gram,NPK $=5$ gram,Urea $=20$ gram.

c. Pengujian 7 hari (Fermentasi dengan waktu 168), dengan komposisi (enzym, ragi, NPK, urea). Air $=15 \mathrm{~kg}$,Singkong $=10 \mathrm{~kg}$,Enzym Alfa Amylase $=10 \mathrm{ml}$,Enzym Gluco Amylase $=10$ $\mathrm{ml}$, Ragi $=15$ gram,NPK $=5$ gram,Urea $=20$ gram.

Setelah tepat pada waktu yang telah ditentukan keluarkan cairan fermentasi dari fermentor kemudian saring untuk memisahkan limbah padat (sludge) dan cairan yang sudah mengandung etanol berkadar rendah (2-5\%). Cairan hasil fermentasi ini disebut cairan Bir.

Destilasi atau dikenal penyulingan dilakukan untuk memisahkan alkohol dari cairan beer hasil fermentasi. Dalam proses destilasi, pada suhu $78^{\circ} \mathrm{C}$ (setara titik didih alkohol) etanol akan menguap terlebih dahulu dibandingkan dengan titik didih air yang mempunyai titik didih $100^{\circ} \mathrm{C}$. Uap etanol didalam distilator akan dialirkan kedalam kondensor sehingga terkondensasi menjadi cairan etanol. Penyulingan etanol dapat dilakukan dengan cara : 
a. Penyulingan menggunakan teknik dan destilator (konvensional) dengan cara tersebut hanya dapat menghasilkan etanol berkadar rendah antara 20-30\%

b. Penyulingan menggunakan teknik dan destilator model reflux (model kolom). Dengan cara ini dapat menghasilkan etanol dengan kadar $60-95 \%$ melalui proses berulang.

\section{HASIL PENELITIAN DAN PEMBAHASAN}

Dari hasil pengujian tingkat keefektifan mesin destilator model reflux akibat lama fermentasiterhadap kadar keluarnya etanol pada mesin distilasi, dapat dilihat pada tabel berikut:

Tabel 1. Data analisa tingkat keefektifan mesin destilator model reflux akibat lama fermentasi

\begin{tabular}{|c|c|c|c|c|c|c|}
\hline \multirow{2}{*}{ No } & \multirow{2}{*}{ Lama Fermentasi } & \multirow{2}{*}{$\begin{array}{c}\text { Suhu di } \\
\text { Reflux }\end{array}$} & \multicolumn{4}{|c|}{ Uji Replikasi (\%) } \\
\hline & & & 1 & 2 & 3 & Rata-rata \\
\hline \multirow{2}{*}{1} & \multirow{2}{*}{3 hari } & $83^{0}$ & 85 & 85 & 85 & 85 \\
\hline & & $83^{0}$ & 92 & 92 & 92 & 92 \\
\hline \multirow{2}{*}{2} & \multirow{2}{*}{5 hari } & $83^{0}$ & 90 & 90 & 90 & 90 \\
\hline & & $83^{0}$ & 93 & 93 & 93 & 93 \\
\hline \multirow{2}{*}{3} & \multirow{2}{*}{7 hari } & $83^{0}$ & 92 & 92 & 92 & 92 \\
\hline & & $83^{0}$ & 92 & 92 & 92 & 92 \\
\hline
\end{tabular}

Dari tabel 1 diketahui lama fermentasi 3 hari pada suhu di reflux $83^{0}$ menghasilkan kadar etanol rata-rata $88,5 \%$ (pada tabel 3). Pada lama fermentasi 5 hari pada suhu yang sama menghasilkan kadar etanol rata-rata 91,5\% (pada tabel 7). Dan lama fermentasi 7 hari pada suhu yang sama menghasilkan kadar etanol rata-rata $92 \%$ (pada tabel 8).

Tabel 2 Perhitungan rata-rata kadar

\begin{tabular}{|c|c|c|c|c|}
\hline \multirow{2}{*}{ No } & \multicolumn{4}{|c|}{ Lama Fermentasi } \\
\hline & & (3 hari) & (5 hari) & (7 hari) \\
\hline \multirow{2}{*}{1} & \multirow[b]{2}{*}{ Kadar } & 85 & 90 & 92 \\
\hline & & 92 & 93 & 92 \\
\hline 2 & $\Sigma$ & 177 & 183 & 184 \\
\hline 3 & $\bar{x}$ & $174 / 2=88,5$ & $182 / 2=91,5$ & $184 / 2=92$ \\
\hline
\end{tabular}

Tabel 3. Perhitungan simpangan rata-rata (mean deviasi) pengujian 1

\begin{tabular}{cccc}
\hline No & Lama Fermentasi & $X$ & {$[X-\bar{x}]$} \\
\hline 1 & 3 hari & 85 & $85-88,5=3,5$ \\
2 & $\sum$ & 92 & $92-91=1$ \\
3 & $\bar{x}$ & 177 & 4,5 \\
\hline
\end{tabular}

Tabel 4. Perhitungan simpangan rata-rata (mean deviasi) pengujian 2

\begin{tabular}{cccc}
\hline No & Komposisi & $X$ & {$[X-\bar{x} \mid$} \\
\hline \multirow{2}{*}{1} & 5 hari & 90 & $90-91,5=1,5$ \\
2 & $\sum$ & 93 & $93-91,5=1,5$ \\
3 & $\bar{x}$ & 183 & 3 \\
\hline
\end{tabular}

Tabel 5. Perhitungan simpangan rata-rata (mean deviasi ) pengujian 3

\begin{tabular}{cccc}
\hline No & Komposisi & $X$ & $|X-\bar{x}|$ \\
\hline 1 & 7 hari & 92 & $92-92=0$ \\
2 & $\sum$ & 92 & $92-92=0$ \\
3 & $\bar{x}$ & 184 & 0 \\
\hline
\end{tabular}


Tabel 6. Perhitungan simpangan baku (standar deviasi) pengujian 1

\begin{tabular}{ccccc}
\hline No & Komposisi & $X$ & $(X-\bar{x})$ & $(X-\bar{x})^{2}$ \\
\hline \multirow{2}{*}{3} & 3 hari & 85 & $85-88,5=3,5$ & $3,5^{2}=12,25$ \\
2 & $\Sigma$ & 92 & $92-88,5=4,5$ & $4,5^{2}=20,25$ \\
3 & $\bar{x}$ & 177 & & 22,5 \\
\hline
\end{tabular}

Tabel 7. Perhitungan simpangan baku (standar deviasi) pengujian 2

\begin{tabular}{ccccc}
\hline No & Komposisi & $X$ & $(X-\bar{x})$ & $(X-\bar{x})^{2}$ \\
\hline 1 & 5 hari & 90 & $90-91=1$ & $1^{2}=1$ \\
2 & $\sum$ & 93 & $93-91,5=1,5$ & $1,5^{2}=2,25$ \\
3 & $\bar{x}$ & 183 & & 3,25 \\
\hline
\end{tabular}

Tabel 8. Perhitungan simpangan baku (standar deviasi) pengujian 3

\begin{tabular}{ccccc}
\hline No & Komposisi & $X$ & $(X-\bar{x})$ & $(X-\bar{x})^{2}$ \\
\hline 1 & 7 hari & 92 & $92-92=0$ & $92^{2}=0$ \\
2 & $\Sigma$ & 92 & $92-92=0$ & $92^{2}=0$ \\
3 & $\bar{x}$ & 184 & & 0 \\
\hline
\end{tabular}

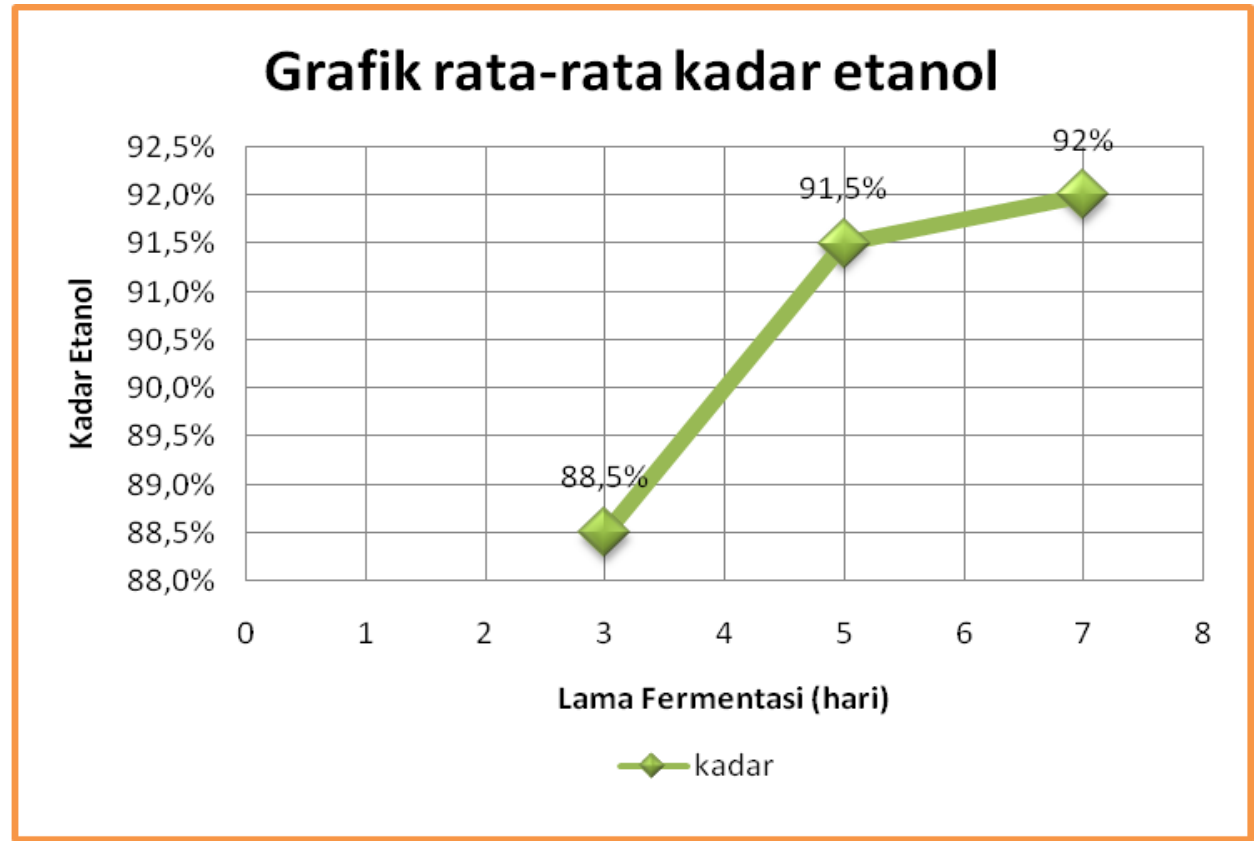

\section{Gambar 2. Grafik Rata-Rata Kadar Etanol}

Berdasarkan rata-rata kadar hasil etanol digambarkan pada grafik, dapat diperlihatkan pada grafik bahwa kadar alkohol tertinggi diperoleh pada waktu fermentasi 7 dengan kadar etanol sebesar $92 \%$. Selanjutnya pada waktu fermentasi 5 hari kadar etanol 91,5\% dan yang paling rendah adalah pada waktu 3 hari dengan kadar etanol 88,5 \%. Hal ini disebabkan karena jumlah mikroba dipengaruhi oleh waktu fermentasi, yaitu semakin lama fermentasi berlangsung jumlah mikroba juga akan semakin banyak sehingga alkohol yang dihasilkan juga semakin banyak. Proses ini akan terhenti jika kadar alkohol sudah meningkat sampai tidak dapat ditolerir lagi oleh mikroba.

Sehingga dengan semakin meningkatnya jumlah mikroba maka semakin banyak pula karbohidrat yang terurai menjadi alkohol. Dengan menigkatnya jumlah alkohol ini maka secara otomatis berat atau densitas dari pada campuran alkohol dan air akan semakin rendah. 


\section{KESIMPULAN}

1) Lama fermentasi mempengaruhi kadar etanol hasil distilasi.

2) Dari hasil data pengujian perbandingan 3, 5, dan 7 hari diketahui yang menghasilkan rata-rata kadar etanol paling tinggi yaitu pengujian 7 hari yang menghasilkan kadar $92 \%$.

\section{DAFTAR PUSTAKA}

[1] Asngad A. dan Suparti, 2009. Lama Fermentasi Dan Dosis Ragi Yang Berbeda Pada Fermentasi Gaplek Ketela Pohon (Manihot Utilissima, Pohl) Varietas Akibat Terhadap Kadar Glukosa Dan Bioetanol, Universitas Muhammadiyah Surakarta.

[2] Hapsari M. A. dan Pramashinta A. 2013. Pembuatan bioetanol dari singkong karet (manihot Glaziovii) untuk bahan bakar kompor rumah tanggaSebagai upaya mempercepat konversi minyak tanahKe bahan bakar nabati, Universitas Diponegoro.

[3] Margono, 1993. Reaksi kimia fermentasi, PT Gramedia Pustaka Utama, Jakarta.

[4] Marques S, 2006. Conversion of recycled paper sludge to ethanol by SHF and SSF using Pichia stipitis.Departamento de Biotecnologia, INETI, Estrada do Paço do Lumiar 22, 1649-038 Lisboa, Portugal.

[5] Murdiyatmo U, 2006. Pengembangan Industri Etanol: Prospek, Kendali dan Tantangan; Workshop National Bisnis Biodiesel dan Bioetanol di Indonesia, Jakarta.

[6] Muttaqin A, 2014. Pernacangan Mesin Destilator Kapasitas Ketel 250 Liter, Proyek Akhir Universitas Muria Kudus.

[7] Pratama H, 2014. Analisa Perbandingan Komposisi Fermenter Pada Proses Fermentasi Ketela Pohon Terhadap Volume Hasil Destilasi Etanol Dengan Mesin Destilator Sederhana, Proyek Akhir Uiversitas Muria Kudus.

[8] Suprapti M. L. 2005. Tepung Tapioka. Kanisius. Yogyakarta.

[9] Widiasa I. N. 2005. Hidrolisis Pati Tapioka pada Fermentasi Tinggi dalam Bioreaktor Membran Enzimatik. Tesis. ITB. Bandung. 